\title{
Hereditary breast and ovarian cancer susceptibility genes (Review)
}

\author{
HIROSHI KOBAYASHI, SUMIRE OHNO, YOSHIKAZU SASAKI and MIYUKI MATSUURA \\ Department of Obstetrics and Gynecology, Nara Medical University, Kashihara, Nara 634-8522, Japan
}

Received April 9, 2013; Accepted May 20, 2013

DOI: $10.3892 / o r .2013 .2541$

\begin{abstract}
Women with hereditary breast and ovarian cancer (HBOC) syndrome represent a unique group who are diagnosed at a younger age and result in an increased lifetime risk for developing breast, ovarian and other cancers. This review integrates recent progress and insights into the molecular basis that underlie the HBOC syndrome. A review of English language literature was performed by searching MEDLINE published between January 1994 and October 2012. Mutations and common sequence variants in the BRCA1 and BRCA2 (BRCA) genes are responsible for the majority of HBOC syndrome. Lifetime cancer risks in BRCA mutation carriers are $60-80 \%$ for breast cancer and $20-40 \%$ for ovarian cancer. Mutations in BRCA genes cannot account for all cases of HBOC, indicating that the remaining cases can be attributed to the involvement of constitutive epimutations or other cancer susceptibility genes, which include Fanconi anemia (FA) cluster (FANCD2, FANCA and FANCC), mismatch repair (MMR) cluster (MLH1, MSH2, PMS1, PMS2 and MSH6), DNA repair cluster (ATM, ATR and CHK1/2), and tumor suppressor cluster (TP53, SKT11 and PTEN). Sporadic breast cancers with TP53 mutations or epigenetic silencing (hypermethylation), ER- and PgR-negative status, an earlier age of onset and high tumor grade resemble phenotypically BRCA1 mutated cancers termed 'BRCAness', those with no BRCA mutations but with a dysfunction of the DNA repair system. In conclusion, genetic or epigenetic loss-of-function mutations of genes that are known to be involved in the repair of DNA damage may lead to increased risk of developing a broad spectrum of breast and ovarian cancers.
\end{abstract}

\section{Contents}

1. Introduction

2. Materials and methods

Correspondence to: Professor Hiroshi Kobayashi, Department of Obstetrics and Gynecology, Nara Medical University, 840 Shijo-cho, Kashihara, Nara 634-8522, Japan

E-mail: hirokoba@naramed-u.ac.jp

Key words: hereditary breast and ovarian cancer, pathogenesis, BRCA, DNA repairs
3. Current understanding of HBOC susceptibility gene

4. Epigenetic silencing

5. Lynch syndrome

6. Prevention

7. Screening

8. Discussion

\section{Introduction}

Breast cancer and ovarian cancer develop through multiple molecular pathways guided by genetic and epigenetic clonal selections. Both cancers have been recognized as a heterogeneous disease with regard to clinical and biological properties. The majority of cancer cases are considered sporadic-appearing tumors in nature because there is no obvious family history, but a number of families with a known genetic cause or inherited predisposition to cancer have been identified (1). Individuals who carry an inherited genetic mutation and epigenetic aberrations in the tumor suppressor genes have an increased lifetime risk of developing cancer. Germline mutations in cancer susceptibility genes cause cancer if the wild-type allele is lost or inactivated. Breast and ovarian cancers (5-10\%) may be hereditary and occur in cancer prone syndromes (2-7). Patients predisposed to breast and ovarian cancers are known as the hereditary breast and ovarian cancer (HBOC) syndrome.

HBOC syndrome is an autosomal dominantly inherited disease characterized by a young age of onset, more than one synchronous or metachronous tumor, and a family history of first and second degree relatives with similar cancers (8). Mainly HBOC syndrome results from germline mutations in breast cancer genes BRCA1 or BRCA2. Other genes or low penetrance alleles might be associated with the HBOC phenotype (9). There is an increasing understanding that the interrelationship between BRCA gene cluster and Fanconi anemia (FA), mismatch repair (MMR) and DNA repair gene status plays a key role in the pathogenesis of cancer predisposition syndromes. We reviewed the HBOC syndrome and current knowledge of inherited susceptibility genes.

\section{Materials and methods}

A computerized literature search was performed to identify relevant studies reported in the English language. We searched MEDLINE electronic databases (http://www.ncbi. nlm.nih.gov/sites/entrez) published between January 1994 and 
October 2012, combining the keywords 'hereditary breast and ovarian cancer', 'pathogenesis', 'BRCA' and 'DNA repair'. Various combinations of the terms were used, depending on the database searched. Each gene was also linked to NCBI Entrez Gene pages (http://www.ncbi.nlm.nih.gov/sites/entrez). Additionally, references in each article were searched to identify potentially missed studies.

\section{Current understanding of HBOC susceptibility genes}

BRCA1 and BRCA2. The breast cancer-associated genes BRCA1 on chromosome $17 \mathrm{q}$ and BRCA2 on chromosome $13 \mathrm{q}$ are the most well-known breast cancer susceptibility genes $(4,5)$. The HBOC syndrome is linked to the BRCA1 gene and, to a lesser extent, to the BRCA2 gene. Germline mutations in these genes account for $2-5 \%$ (up to $10 \%$ ) of all breast cancers and all ovarian cancers. Mutations were present with a frequency of more than $10 \%$ in the high risk populations, including patients with a family history of breast or first-degree ovarian cancer, those with bilateral breast cancer, multiple organ cancer including younger breast cancer patients (aged $<35$ years). Mutations in the BRCA1 and BRCA2 genes are responsible for $\sim 60 \%$ (up to $85 \%$ ) of $\mathrm{HBOC}$. Women carrying a BRCA1 or BRCA2 genetic mutation have $60-80 \%$ and $20-40 \%$ lifetime risk of developing breast cancer and ovarian cancer, respectively. More modest increases in risk for other cancers have been noted: additional sites included stomach, pancreas, prostate and colon. The cancer risk ranged from 20 to $60 \%$, with the greatest increases in cancer risk in stomach and pancreas. BRCA mutations were also associated with increased risks for leukemia and lymphoma (10).

A recent study showed that breast cancer patients belonging to a population with a high probability of being BRCA1 carriers showed a better prognosis compared with those with sporadic breast cancer (11). Furthermore, BRCA1 and BRCA2-related invasive epithelial ovarian cancers have a better 5-year overall survival compared with sporadic ovarian cancers (12). The 5-year overall survival was better in BRCA2 carriers compared to BRCA1 carriers (36\% for non-carriers, $44 \%$ for BRCA1 carrier and 52\% for BRCA2 carriers).

The mutations include partial or complete gene deletions, duplications, large insertions, splice alteration, frameshifts as well as missense and nonsense mutations. Deletions or insertions usually lead to abnormal structure and function. Germline mutations are usually pathogenic point mutations, and are scattered throughout their coding regions. The potential hot-spot mutations within BRCA 1 and BRCA2 are uncommon. The previously described mutations were identified in the Breast Cancer Information Core website (BIC, http://research. nhgri. nih. gov/bic/). More than 3500 mutations have been reported throughout both genes. Data from subjects with a variety of ethnic backgrounds altered the overall odds of BRCA mutation carrier status. The spectrum of mutations is different depending on the race. The mutations are detected in $10-12 \%$ of Ashkenazi Jewish women diagnosed with breast cancer. Ashkenazi Jewish subjects are observed at increased frequency compared to other Caucasian, because this population harbors ancient BRCA1 and BRCA2 mutant alleles. Mutation analysis revealed the c. 5266dup (until recently referred in the literature as 5382insC), c. 68_69del (185delAG) and 4153delA mutations in BRCA1 and c. 5946del (6174delT) mutation in BRCA2 (13). BRCA gene founder mutations such as BRCA1c. 5266dup mutation, BRCA2999del5 mutation and BRCA1delexon17 have also been described in other populations, including the Slavic, Finnish, Icelandic and German populations, respectively.

The tumor suppressor BRCA1 and BRCA2 genes are essential components of the double-strand break (DSB) repair by homologous recombination (HR) system. Targeting tumor suppressor loss-of-function is possible based on the concept of synthetic lethality. Thus, the synthetically lethal effect might be observed in tumors defective in BRCA1 or BRCA2 that are required for efficient $\mathrm{HR}$, indicating that ovarian cancer patients carrying germ-line mutations had improved rates of progression-free and overall survival (12). Chromosomal rearrangements might be formed as a consequence of these error-prone DSB repairs and lead to the development of genomic instability. Large genomic rearrangements have been identified in HBOC families and account for 8-15\% of deleterious BRCA mutations, but these rearrangements may escape detection (14). The issue is that BRCA genetic testing done through sequencing will not capture large rearrangements in these genes.

BRCA1 functions as a tumor suppressor gene, but paradoxically, BRCA1 knockout mice are embryonically lethal in homozygous state. Lack of BRCA1 is thought to result in cellular lethality, suggesting that BRCA1 regulates stem/progenitor cell proliferation and differentiation. For cell differentiation, BRCA1 regulates apicobasal polarity, together with several genes such as RHAMM (hyaluronanmediated motility receptor), AURKA (aurora kinase A) and TPX2 (microtubule-associated, homolog). Intracellular RHAMM associates with BRCA1 and BARD1 (BRCA1 associated RING domain 1). The complex attenuates the mitotic-spindle-promoting activity of RHAMM that might contribute to tumor progression. BRCA1 also binds and regulates AURKA, a cell cycle-regulated kinase that appears to be strongly involved in centrosome regulation. Genetic variants in the AURKA gene may contribute to breast cancer development (5). BRCA1 further accumulates TPX2 and is required for mitotic spindle-pole assembly. BRCA-associated nuclear core complex proteins are required for the functional integrity of the pathway of not only DNA damage response and repair, but also cell differentiation

From a clinical point of view, the triple-negative breast cancer characterized by the absence of estrogen receptor (ER), progesterone receptor (PgR), and HER2 (also known as ERBB2) accounts for $\sim 15 \%$ of breast cancers and is diagnosed more frequently in younger women (15). Compared with the ER/PR-positive tumors, triple-negative breast cancershowed a greater risk for recurrence and shortened survival. Triple-negative breast cancer was frequently associated with mutations in BRCA genes: the incidence was 12.5-20\% (16). Women with an early age-of-onset triple-negative breast cancer are more likely to be associated with deleterious mutations in BRCA1 and BRCA2 genes (17). Even in non-BRCA gene mutations, a subset of triple-negative tumors shares multiple clinicopathologic features and phenotype with BRCA-mutated breast cancers. They harbor dysfunctional DNA repair mechanisms, but the nature of this link remains opaque. A subset 
of HBOC syndrome also contain mutations in the TP53 gene, and the TP53 loss-of-function tumors have a low frequency of HER2 expression (18).

The predominant histologic type of ovarian cancers associated with the HBOC syndrome was high-grade serous carcinomas of the ovary. There were no significant differences in ovarian cancer morphology between BRCA1 and BRCA2 carriers (19). Ovarian cancer patients with BRCA mutations were associated with an increased chemosensitivity and improved overall survival, but some investigators failed to confirm improved survival.

Modifying hereditary breast and ovarian cancer risks. Mutations in BRCA1 and BRCA2 do not account for all cases of HBOC, implicating that the remaining cases can be attributed to the involvement of other susceptibility genes. Other genes, including Fanconi anemia (FA) cluster (FANCD2, FANCA and FANCC), MMR cluster (MLH1, MSH2, PMS1, PMS2 and MSH6), DNA checkpoint cluster (ATM, ATR and CHK1/2), and tumor suppressor cluster (TP53, SKT11 and PTEN) have been associated with increased risk of breast and ovarian cancer as part of other cancer syndromes. The contribution of mutations in other genes to the burden of breast or ovarian cancer is indicated in Table I.

Poly(ADP-ribose) polymerase (PARP). Poly(ADP-ribose) polymerase (PARP) is an enzyme involved in the recovery of cells from DNA damage and the regulation of the molecular events such as BER, a key pathway in the repair of DNA single-strand breaks (SSB). The inhibition of PARP leads to the induction of synthetic lethality and cell death by targeting HR-mediated DNA repair deficient tumors (20). Tumors that lack functional BRCA1, BRCA2, or TP53 are hypersensitive to inhibition of PARP. Several proteins involved in HR on sensitivity to PARP inhibition may include BRCA cluster (RAD51C, RAD51D and RAD54), FA cluster (FANCD2, FANCA and FANCC), Cdk cluster, nucleotide excision repair (NER) cluster (RPA1 and NBN), DNA repair checkpoint cluster (ATR, ATM, CHK1 and CHK2) and TP53 cluster. Therefore, therapeutic approach using PARP inhibitors may be feasible for BRCA dysregulated tumors and appear promising in a variety of cancer types, including breast and ovarian cancers. The presence of these germline mutations and epimutations types might be a hallmark of BRCAness and a potential biomarker for sensitivity to PARP inhibition.

Recently, Kaye et al (21) reported the results of a phase II study comparing the efficacy and safety of olaparib, a potent oral PARP inhibitor, in patients with germ-line BRCA mutations and recurrent ovarian cancer. Unfortunately, there was no remarkable differences in PFS between the olaparib and pegylated liposomal doxorubicin groups. Another clinical study demonstrated that olaparib applied as maintenance treatment prolonged PFS, but not OS, in patients with advanced and platinum-sensitive, recurrent, high-grade serous ovarian cancer (22).

BER and NER. There are two types of DNA repair proteins: the nucleotide excision repair (NER) pathway (ERCC1, excision repair cross-complementing rodent repair deficiency, complementation group 1) and the base excision repair (BER) pathway (XRCC1, X-ray repair complementing defective repair in Chinese hamster cells 1) (23). The NER pathway is responsible for the removal of bulky DNA lesions. NER is a defense system against various types of DNA damage and necessary for maintaining genomic stability. RPA1, replication protein A1, is a single-stranded DNA binding protein and participates in the recruitment of the two structure-specific DNA endonucleases, XPG (xeroderma pigmentosum, also known as ERCC5) and XPF (xeroderma pigmentosum, complementation group F)-ERCC1 complex, which makes the 5 incision in NER. The XPF-ERCC1 complex is essential for cutting the damaged DNA strand and the DNA repair by the NER pathway. NBN (nibrin, also known as NBS1) was involved in DNA DSB repair and DNA damage-induced checkpoint activation as a component of the MRE11-RAD50-NBS1 complex. Mutations in NBN is thought to be associated with breast-cancer risk.

Furthermore, XRCC1 is involved in the repair of DNA SSB and oxidative damage (23). This protein interacts with DNA ligase III, polymerase $\beta$ and PARP1 participating in the BER pathway. Reduced XRCC1 expression may confer chemoradiation and leads to improved patient survival.

\section{Epigenetic silencing}

Between $50-80 \%$ of HBOC syndrome can be explained by defective germline mutations in BRCA1 and BRCA2 as well as, to a lesser degree, other genes described above, but for the remaining families the factors driving susceptibility remain unknown (24). Approximately one third of the HBOC families do not have evidence of the germline mutations in BRCA1 and BRCA2. The loss of BRCA function might be due to either germline/somatic mutation or epigenetic silencing. Since little is known about the contribution of epimutations to the remaining BRCA1/2 mutation-negative cases, epigenetic silencing has been explored in HBOC syndrome. The activities of tumor suppressor genes and cancer susceptibility genes could be influenced by genetic and epigenetic alterations. Decreased expression of cancer susceptibility genes has been observed in sporadic breast and ovarian cancer where it is often associated with the aberrant epimutations or hypermethylation of the BRCA1 and BRCA2 genes. The loss of BRCA1 function due to somatic hypermethylation explained $\sim 10 \%$ of sporadic breast cancer cases. A subset of the sporadic tumor patients demonstrated hypermethylation of BRCA2 and their interacting protein including HP1 $\gamma$ (heterochromatin protein 1gamma), RAD51C, ATM and PALB2 (25). Based on BRCA1 deletion, TP53 mutations, ER- and PgR-negative status, young age at diagnosis and high grade tumor, phenotypic features of sporadic breast cancers resemble BRCA1 mutated cancers termed 'BRCAness'. Phenotypic similarities were most closely observed in BRCAness, epigenetic silencing and deletion of the BRCA1 and BRCA2 genes.

\section{Lynch syndrome}

Many genes have been implicated in the DNA damage response pathways where the BRCA1 and BRCA2 genes are involved. Genetic susceptibility to cancer is attributed to deleterious germline mutations in the DNA mismatch repair (MMR) genes. Another important non-BRCA1/BRCA2 
Table I. Modifying hereditary breast and ovarian cancer risks.

No. Genes Functions $\quad$ Refs.

Genes with high penetrance

$1 \mathrm{CDH} 1$, Loss of $\mathrm{CDH} 1$ function contributes to progression in cancer by increasing proliferation, cadherin 1 invasion, metastasis and epithelial-mesenchymal transition (EMT). Germline mutations type 1 in the $\mathrm{CDH} 1 / \mathrm{E}$-cadherin gene predispose to the development of the autosomal hereditary E-cadherin diffuse gastric cancer (HDGC) syndrome, which leads to the development of breast, colorectal, thyroid and ovarian cancer (46). Gastric cancer risk is also elevated in HBOC, in Lynch syndrome (due to germline mutations in DNA mismatch repair genes), in familial adenomatous polyposis (FAP) [germline adenomatosis polyposis coli (APC) mutations], in Li-Fraumeni syndrome (germline p53 mutations), in Peutz-Jeghers syndrome (germline STK11 mutations), and in juvenile polyposis syndrome [germline mutations in the SMAD family member 4 (SMAD4) and bone morphogenetic protein receptor, type IA genes (BMPR1A)] (47).

2 NBS1, also The encoded protein nibrin is an integral member of the MRE11/RAD50/NBN (MRN) known as complex essential for processing DNA double-strand breaks and DNA damage-induced NBN (nibrin) checkpoint activation. Mutations in this gene causes Nijmegen breakage syndrome, an autosomal recessive chromosomal instability syndrome characterized by microcephaly, growth retardation, immunodeficiency, and cancer predisposition. The NBN 657del5 mutation plays a role in breast cancer risk, but not ovarian cancer risk.

$3 \quad \mathrm{NF} 1$ NF1 functions as a negative regulator of the Ras/Raf/Erk signal transduction pathway. neurofibromin 1 Mutations in this gene are associated with neurofibromatosis type 1 (NF1) and other neoplasms, including juvenile myelomonocytic leukemia (JMML) and breast cancer (48).

4 PTEN, PTEN, a tumor suppressor gene, is mutated in a large number of cancers at high frequency. phosphatase and PTEN is a phosphatidylinositol 3-phosphatase and functions as a tumor suppressor by tensin homolog negatively regulating AKT signaling pathway. Mutations in PTEN gene are associated with the development of Cowden syndrome and also correlated with hamartomatous polyps, early-onset breast, thyroid and endometrial cancers (49).

5 TP53, tumor The encoded protein 53 responds to diverse cellular stresses to maintain genetic stability, protein $\mathrm{p} 53$ thereby inducing cell cycle arrest, apoptosis, senescence, DNA repair, or changes in metabolism. Mutations, loss of heterozygosity (LOH), overexpression and loss of TP53 function occur as somatic mutations in human malignancies at high frequency. TP53 loss-of-function is essential for BRCA1-associated tumorigenesis (18). The mutation frequency of 53 in the three groups were sporadic ovarian cancers, 50\%; somatic BRCA1 mutations, $90 \%$ and germline BRCA1 mutations, $80 \%$ (50). Germline mutations in TP53 are associated with hereditary cancers such as Li-Fraumeni syndrome, characterized by predisposition to multiple cancers.

6 STK11, STK11 regulates cell polarity and functions as a tumor suppressor. Germline mutations in serine/threonine STK11 gene is associated with Peutz-Jegher syndrome, an autosomal dominant disorder kinase 11 characterized by the growth of polyps in the gastrointestinal tract, pigmented macules on the skin and mouth, and cancer susceptibility in various organs including testis, ovary, endocervix, breast, pancreas and colon.

Genes with moderate penetrance

7 ATM, ataxia telangiectasia mutated
The protein encoded by this gene belongs to the PI3/PI4-kinase family. The activation of ATM was mediated via interactions with a wide variety of downstream proteins, including checkpoint kinase CHK2, checkpoint proteins RAD17 and RAD9, and DNA repair protein NBN (51). ATM-mediated CHK2 kinase phosphorylation activates a variety of downstream downstream substrates, including the CDC25C (cell division cycle 25 homolog C), TP53, and BRCA1 gene products, which are required for the induction of G2/M cell cycle arrest 
Table I. Continued.

No. Genes Runctions Refs.

Genes with moderate penetrance

7 ATM, ataxia telangiectasia mutated

8 ATR, ataxia telangiectasia and $\operatorname{Rad} 3$ related

9 CHEK2, checkpoint kinase 2

10 Fanconi anemia (FA) genes

11 FANCJ, Fanconi anemia group $\mathbf{J}$ protein, also known as BRCA1 interacting protein, C-terminal helicase 1

12 PALB2, partner and localizer of BRCA2 and apoptosis after DNA damage. Germline mutations in this gene are associated with ataxia telangiectasia (AT), an autosomal recessive disorder. Polymorphisms in the ATM gene had an evidence for an association between variants in candidate genes and risk of breast cancer (6). A heterozygous variant, IVS10-6T>G, was reported in breast cancer families (52). This variant seems to occur at a lower frequency $(0.83 \%)$ in affected individuals. In contrast to BRCA1 and BRCA2, the CHK2 heterozygosity does not increase the ovarian cancer risk.

ATR also activates several important key proteins, including checkpoint kinase CHK1, TP53, BRCA1, RAD17 and RAD9. Constitutively phosphorylated CHK1 could have activated oncogene signaling pathways including myc signaling. CHK1 phosphorylates the FANCE subunit of the Fanconi anemia (FA) core complex, which is associated with the FA-BRCA pathway (53).

CHEK2, a cell cycle checkpoint regulator, is essential for activation in response to DNA damage. CHEK2 inhibits CDC25C phosphatase, stabilizes p53, and leads to cell cycle. arrest in G1. Since mutations in CHEK2 gene such as c.470T>C and c.1100delC increase the risk of HBOC, CHEK2 has been identified as an breast cancer susceptibility gene in the high-risk BRCA1/2-founder mutation-negative individuals (54).

Mutations of Fanconi anemia (FA) genes have been demonstrated to cause breast and ovarian cancer susceptibility in cases from non-BRCA1/BRCA2 families (55). FA is a rare autosomal or X-linked recessive genetic heterogeneous disorder characterized by spontaneous chromosomal breaks, abnormal DNA repair and clinical problems including congenital abnormalities, endocrinopathies, early onset bone marrow failure and an increased susceptibility to cancer and leukemia (36). Similar to BRCA, the FA proteins form a functional core complex and are associated with a novel pathway required for DNA damage repair, particularly DNA interstrand cross-links. Owing to the link between FA and BRCA genes, this pathway is often referred to as the FA-BRCA pathway. FA proteins interact with each repair machinery such as that involved in HR, base excision repair (BER), nucleotide excision repair (NER), or MMR complex. As DNA damage response, the pathway-specific driver proteins have been shown to co-localize in nuclear foci with the FA core complexes such as FANCJ (BACH1)-BRCA1 and FANCN (PALB2)-BRCA1/2.

FANCJ is the BRCA1 associated C-terminal helicase (BACH1). The BRCA1-FANCJ interaction is required for promoting error-free repair, DNA DSB repair, and interstrand cross-links repair by linking to MMR protein complex MLH1-PMS2 (MutL $\alpha$ ) and checkpoint control. Tumors associated with FANCJ mutations will compromise error free NHEJ (non-homologous end-joining) and resemble BRCA1-associated cancer (56).

PALB2 (the partner and localizer of BRCA2), also known as FANCN, was identified as a BRCA1- and BRCA2-interacting protein. PALB2 is associated with the formation of the BRCA1-PALB2-BRCA2 complex and has rare, but moderate-risk for breast cancer (57). FANCD1 was identical to BRCA2. The FA complex is also required for the monoubiquitination of FANCD2. Furthermore, FANCD2 interacts with the MMR complex proteins MSH2 and MLH1. FANCD2 inactivation confers a hypersensitivity towards DNA cross-links and oxidative stress (58). Increased sensitivity to DNA crosslinking agents was attributable to defective MSH2 or MLH1 function. Recent evidence 
Table I. Continued.

No. Genes Runctions

12 PALB2, partner and localizer of BRCA2

13 CDK1, cyclin-dependent kinase

14 RAD50, RAD50 homolog

16 LSP1, lymphocyte-specific protein 1

17 MAP3K1, mitogenactivated protein kinase kinase kinase 1

E3 ubiquitin protein ligase

18 TGFB1, transforming growth factor, $\beta 1$

19 TOX3, TOX high mobility group box family member 3 indicated that mutations in FANCD1 (BRCA2), FANCD2, FANCJ and FANCP have a role in breast and ovarian cancer susceptibility. Although clinical manifestations vary widely from patient to patient, individuals with FA are predisposed to develop breast and ovarian cancer than those without FA.

Cyclin-dependent kinase (CDK) is the driver for cell cycle progression. CDK was generally suppressed in response to DNA damage, but certain CDK seems necessary for proper DNA damage response. CDK1 phosphorylates BRCA1, and is essential for efficient formation of BRCA1 foci (59). CDK1 governs the G2/M transition. Depletion or inhibition of CDK1 results in deficient DNA damage response signaling and DNA repair by $\mathrm{HR}$, suggesting that CDK1 may interfere with DNA damage response. As expected, combined inhibition of CDK1 and PARP in BRCA-wild-type cancer cells resulted in efficient tumor regression in a preclinical model (59).

Other predisposition genes involved in DNA repair may account for a proportion of HBOC families. RAD genes are involved in DNA DSB repair and required for both types of the repair processes, NHEJ and HR (60). Polymorphic variants and defective mutations of RAD50 may be at a risk of developing breast cancer possibly through the loss-of-function of the MRE11-RAD50-NBN complex, key factors in maintaining genome stability (61). Some patients with an HBOC-like phenotype have mutations in RAD50. Mutations in this gene are the cause of Nijmegen breakage syndrome-like disorder. Heterozygous germline mutations in RAD51C were found in breast and ovarian cancer families (62). Pathogenic RAD51C mutations have also been identified in BRCA1/2 mutation-negative HBOC families (63). A biallelic mutation or a homozygous missense mutation in RAD51C was reported to cause FA-like disorder.

Mutations in the FGFR2 gene cause several disorders, including Crouzon syndrome, Pfeiffer syndrome, craniosynostosis, Apert syndrome, Jackson-Weiss syndrome, Beare-Stevenson cutis gyrata syndrome, Saethre-Chotzen syndrome, and syndromic craniosynostosis. The rs2981582, rs2420946, and rs1219648FGFR2 polymorphisms act as modifiers of breast cancer susceptibility, particularly in the group of non-carriers of BRCA1/2 mutations (64).

LSP1 encodes an intracellular F-actin binding protein and regulates LS neutrophil motility, adhesion to fibrinogen matrix proteins, and transendothelial migration. The LSP1 rs3817198 polymorphism is associated to a modified risk of breast cancer.

MAP3K1 is associated with activation of the ERK and JNK kinase pathways as well as the NF- $\kappa$ B pathway. Functional polymorphism of MAP3K1 rs889312 has been shown to influence the risk of familial and early-onset breast cancer.

Mutations in the TGFB1 gene is a genetic risk factor for Camurati-Engelmann disease featuring histopathological changes of osteomalacia. The rs1982073 TGFB1 polymorphism has been implicated in an elevated risk of progesterone receptor negative breast cancer.

TOX3 is involved in alteration of chromatin structure. The rs 3803662 TOX3 polymorphism is associated with an increased risk of and overall survival in breast cancer. 
Table I. Continued.

\begin{tabular}{|c|c|c|c|}
\hline No. & Genes & Functions & Refs \\
\hline 20 & $\begin{array}{l}\text { VEGF, } \\
\text { vascular endothelial } \\
\text { growth factor }\end{array}$ & $\begin{array}{l}\text { VEGF plays an important role in tumor angiogenesis. Genetic variation in VEGF may } \\
\text { contribute to cancer susceptibility. An association of the CC, CT, or TT genotypes } \\
\text { exhibited modification of breast and ovarian cancer risks. The 936_C>T polymorphism } \\
\text { in the VEGF gene has a functional influence on disease risks in BRCA1 carriers (65). }\end{array}$ & $(65)$ \\
\hline 21 & $\begin{array}{l}\text { PGR, } \\
\text { progesterone } \\
\text { eceptor }\end{array}$ & $\begin{array}{l}\text { The variant progesterone receptor allele named PROGINS polymorphism (rs1042838) } \\
\text { is characterized by a 306-bp Alu insertion into intron } 7 \text { and two additional sequence } \\
\text { variations in exons } 4 \text { and } 5 \text { of the PGR gene, Val660Leu and His } 770 H i s . \text { The presence } \\
\text { of one or more PROGINS alleles has an increased risk of developing ovarian and } \\
\text { endometrial cancers (66). }\end{array}$ & (66) \\
\hline 22 & $\begin{array}{l}\text { KRAS, } \\
\text { v-Ki-ras2 Kirsten } \\
\text { rat sarcoma viral } \\
\text { oncogene homolog }\end{array}$ & $\begin{array}{l}\text { A single amino acid substitution of KRAS, a member of the small GTPase superfamily, } \\
\text { is responsible for an activating mutation and results in various malignancies, including } \\
\text { lung, pancreas and colorectal cancers. Interestingly, the KRAS-variant at rs61764370 } \\
\text { is associated with an increased risk of developing ovarian cancer in HBOC families } \\
\text { without other known genetic abnormalities (67). }\end{array}$ & (67) \\
\hline
\end{tabular}

Germline mutations in BRCA1 and BRCA2 are associated with an increased risk of HBOC syndrome. Non-BRCA mutations only account for a minority of cases. Members of mutation-negative families are also at increased risk of breast and ovarian cancers. Genome-wide association studies identified other genetic factors that increase the risk of breast and ovarian cancers. In addition to BRCA1 and BRCA2 mutations, putative susceptibility genes for hereditary breast and ovarian cancer include BRCA1/2 function modifier genes and DNA repair modifier genes with high penetrance (CDH1, NBS1, NF1, PTEN, TP53 and STK11), moderate penetrance (ATM, ATR, BRIP1,CHEK2, PALB2, CDK1 and RAD50), and low penetrance (FGFR2, LSP1, MAP3K1, TGFB1, TOX3, VEGF, PGR, KRAS and PARP) $(3,68)$. Although some of the factors were validated, various studies suggest the existence of disease susceptibility differences within ethnic populations.

hereditary condition is hereditary non-polyposis colorectal cancer (HNPCC) syndrome, also known as 'Lynch syndrome'. Two manifestations of hereditary ovarian cancer are currently recognized: the HBOC syndrome and the HNPCC syndrome. Lynch syndrome has been defined clinically and genetically and is an autosomal-dominant cancer predisposition syndrome that increases the risk for several forms of malignancy, including colorectal (lifetime cancer risk, 70-80\%), endometrial (50-60\%), stomach cancer (13-19\%), ovarian cancer (9-14\%), small intestine, liver and biliary tract, brain, as well as transitional cell carcinoma of the ureters and renal pelvis. Mutations in four MMR genes [MLH1 (mutL homolog 1), MSH2 (mutS homolog 2), MSH6 (mutS homolog 6) and PMS2 (postmeiotic segregation increased 2)] are associated with Lynch syndrome and account for another $10 \%$ of hereditary ovarian cancer (26). The MMR genes encode proteins involved in the same pathway of DNA mismatch repair. These genetic defects in the DNA MMR system result in DNA replication errors, including base substitutions and insertion-deletion loops, known as microsatellite instability (MSI). MutS $\alpha$ complex (composed of MSH2 and MSH6) or MutS $\beta$ complex (MSH2-MSH3) recognizes single-base mismatches and small insertion-deletion loops, binds to mismatched DNA, and recruits the MutL $\alpha$ complex (MLH1-PMS2), which leads to strand discrimination and removal of the errors and coordinates the remaining steps in MMR (27-29).

Both HNPCC and HBOC associated ovarian cancer develop along distinct genetic pathways (30). Although some deviating reports exist, breast cancer incidence has been found to be elevated in Lynch syndrome patients (31). Furthermore, germline mutations associated with Lynch syndrome has been described in 2-3\% of patients diagnosed with endometrial cancer. Among Lynch syndrome-related cancers, endometrial cancer is riskier than colorectal cancer in terms of estimated lifetime cumulative risk (32). The overall 5-year survival rate for endometrial ( $88 \mathrm{vs.} 82 \%$ ) or ovarian cancer (64 vs. $58 \%$ ) was not significantly different between patients with endometrial or ovarian cancer that are associated with Lynch syndrome and the controls with sporadic cases $(33,34)$. Although immunohistochemical analysis of tumor tissue proved to be a good pre-screening test before proceeding to germline mutation analysis, the discordant results are sometimes observed between immunohistochemistry and replication error phenotyping. Notwithstanding this limitation, immunohistochemistry may be helpful in the evaluation of women with a likely diagnosis of Lynch syndrome. Immunohistochemistry for DNA MMR showed loss of proteins in $9 \%$ of women with synchronous endometrial and ovarian cancer (35).

As shown in Fig. 1, BRCA1 forms a multi-subunit protein complex, which includes DNA damage repair proteins, including FA and MMR proteins. Recent studies showed a functional interaction between FANCJ and the MMR complex MutL $\alpha$, which is essential for establishment of DNA interstrand cross-links (36). FANCD2 is required for binding between MSH2 and MLH1, which are involved in the monoubiquitination of FANCD2, leading to recruitment of ATR and then activation of CHK1 and TP53. Furthermore, MutS $\alpha$ and MutL $\alpha$ complex have been shown to be required for the 


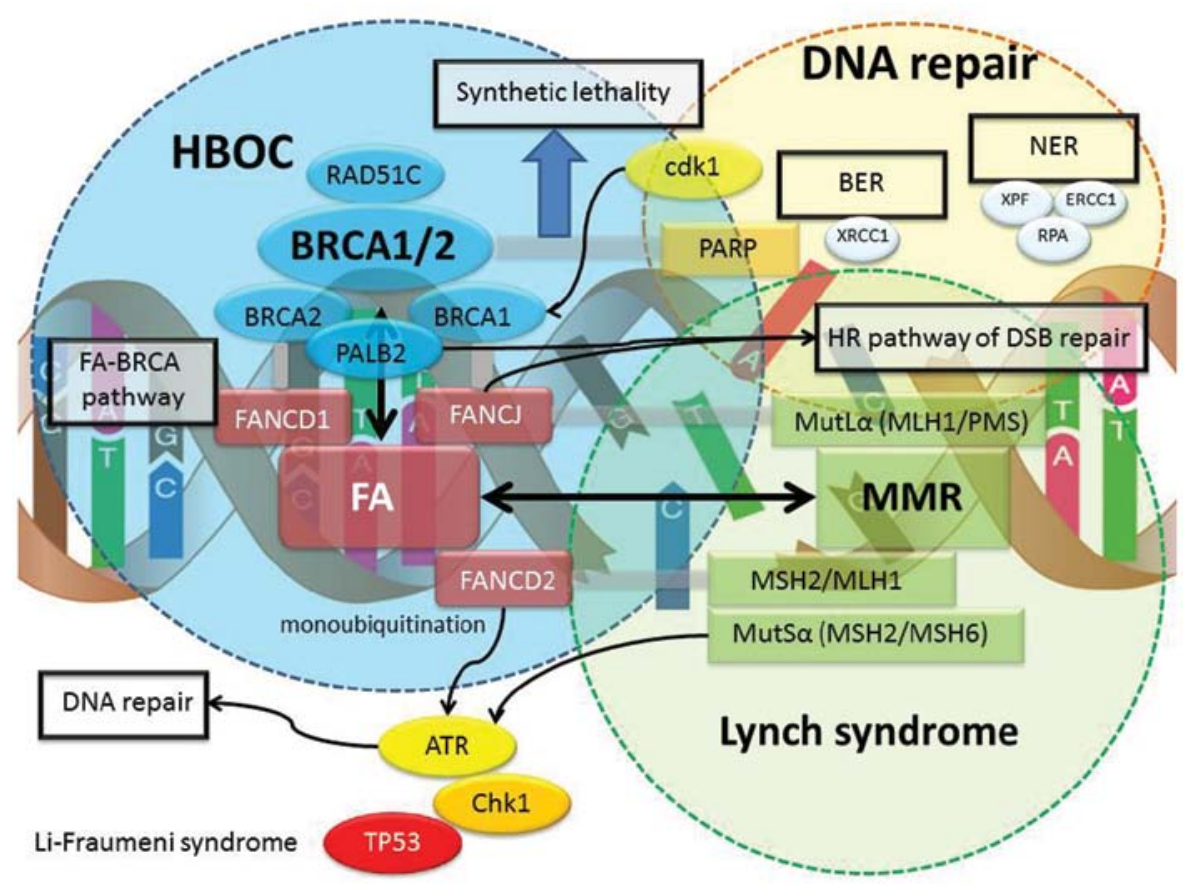

Figure 1. New insights into DNA repair machinery in BRCA pathways or multiprotein networks. We reviewed the breast and ovarian cancer susceptibility genes and their functional multiprotein networks in promoting DNA repair and the underlying molecular mechanisms involving interaction with the FA, MMR and other DNA repair genes in HBOC syndrome. BRCA1 and BRCA2 maintain cellular events associated with the genomic integrity. Mutations that affect the mechanisms involved in the detection, stabilization and repair of DNA damage cause genome instability.

recruitment of ATR to DNA damage lesion. Taken together, these results support that there might be a functional overlap between the MMR and FA-BRCA pathways.

\section{Prevention}

Attention has been paid to the role of modifiable risk factors like reproductive histories and exogenous hormones. Potential modifying factors include age of menarche, parity, breastfeeding and oophorectomy. Oral contraceptives (OCs) have a significant protective effect on the risk of ovarian cancer by $\sim 50 \%$ in the general population (28). OCs reduce the risk of ovarian cancer also in BRCA1/BRCA2 mutation carriers. The effect of parity may be different in BRCA1 and BRCA 2 carriers. Parity protects against breast cancer in BRCA1 mutation carriers. Multiparity may be associated with an increase in risk in BRCA2 carriers. However, the effect of multiparity on ovarian cancer risk for BRCA2 mutation carriers has only been investigated in a small number of studies. Therefore, the association is controversial. Women who took OCs before the age of 30 years and long-term user of 5 or more years have been associated with a slight increase in risk of breast cancer among BRCA1 mutation carriers (29). Furthermore, prolonged hormone replacement therapy (HRT) use is an established risk factor of breast cancer. HRT also affects ovarian cancer risk. Among a subgroup of patients who had a familial history of breast cancer, tamoxifen and raloxifene, selective estrogen receptor modulators, reduced breast cancer risk. Tamoxifen and raloxifene reduced the risk of invasive breast cancer: compared with placebo, raloxifene reduced breast cancer risk by $38 \%$, tamoxifen showed a $50 \%$ reduction (37). Additionally, use of PARP inhibitors is a potential synthetic lethal therapeutic strategy and may be considered as targeted chemoprevention in patients with specific DNA-repair defects. Other agents under preclinical and clinical investigation include cyclooxygenase- 2 inhibitors, aromatase inhibitors, tyrosine kinase inhibitors, and difluoromethylornithine (a polyamine inhibitor) $(38,39)$. Future efficacy studies are expected.

Prophylactic surgeries are appropriate treatment options for BRCA mutation-associated cancer (4). Prophylactic bilateral mastectomy reduces the risk of breast cancer in BRCA mutation carriers by $90 \%$ at any age. Prophylactic bilateral salpingo-oophorectomy (BSO) lowers the ovarian cancer risk by $80 \%$. BSO performed before age 50 years also exhibits a $50 \%$ reduction in subsequent breast cancer risk. In conclusion, prophylactic surgeries lead to a reduction in breast and ovarian cancer-specific mortality. Knowledge of these risk factors and prevention strategies will have a great impact on the management of hereditary breast and ovarian cancers.

\section{Screening}

Since identification of the mutation screening is currently labor intensive and expensive, the screening should be directed to asymptomatic individuals only if they belong to high-risk families. Various safe and effective screening protocols have been recommended for early cancer detection and reduction of cancer risk in clinical practice. Women with HBOC syndrome often utilize the latest medical advances in increased surveillance, prevention, early detection, chemoprevention and optimal treatment. Among BRCA1 and BRCA2 mutation carriers, use of screening mammography alone led to increased early detection rates of non-palpable breast cancer, 
but the rate of interval cancers was high $(7,40)$. Therefore, the effectiveness of mammography alone (sensitivity 40\%) is questionable for screening high-risk women. In the high risk group of women, magnetic resonance imaging (unenhanced MR imaging with combined diffusion-weighted and T2-weighted images, sensitivity $50 \%$ ) surveillance largely out performed mammography. Furthermore, dynamic contrastenhanced MRI exhibited highest sensitivity (86\%) (41). MRI is a better screening method and will detect the majority of breast cancers at an early stage. The addition of MRI to screening mammography increased sensitivity (42), supporting the benefits of breast MRI examination annually (the sensitivity was $80 \%$, the false positive rate was $10 \%$ ) in BRCA mutation carriers (43). Alternating MRI and mammography screening at 6-month intervals might be a clinically effective approach. The HBOC carriers have two options to reduce their risk of ovarian cancer: periodic screening and risk-reducing surgeries (44). Periodic screening consists of annual or semi-annual pelvic examination with the longitudinal CA125 blood test plus concurrent transvaginal ultrasound. Unfortunately, to date, this screening regimen is ineffective for early detection of ovarian cancer in high-risk women. Risk-reducing salpingooophorectomy represents a potentially valuable intervention and is the only way for many women at high-risk by age 40 years, or on completion of childbearing. Preventive surgery can reduce ovarian cancer risk by $80-90 \%$ and breast cancer risk by $50-60 \%$ in BRCA mutation carriers.

\section{Discussion}

HBOC syndrome is the inherited tendency to develop breast, ovarian and other cancers and believed to be transmitted by mutations in the specific genes. Clinical characteristics, including the type of tumor and age at occurrence as well as family history, predict the prevalence of BRCA germline mutations. A number of clinicians usually take into account the age of the youngest breast cancer patient and the number of ovarian cancer cases in a family as well as pathological diagnosis. Up to $80 \%$ of the HBOC cases are due to mutations in BRCA1 or BRCA2 genes. Both BRCA1 and BRCA2 mutations are scattered throughout the whole coding exons.

To maintain and restore the genomic integrity, normal cells possess DNA repair mechanisms. The structural modifications, such as DNA base damage, DNA strand break, inter- and intrastrand crosslinks and DNA-protein crosslinks, are involved in mutation and cancer. A variety of intelligent mechanisms can activate DNA repair pathways and cell cycle checkpoints and recognize and repair SSB or DSB by the master sensors and regulators of DNA damage response such as BRCA1 and BRCA2. BRCA1 and BRCA2 genes were recruited to the sites of DNA damage. BRCA1 associates with several proteins and is an integral member of the repair of DNA damage by functional HR, NER and possibly NHEJ. BRCA1 activated by cdk1 physically interacts with MutL $\alpha$, through the interaction of the FA-BRCA pathway (45). BRCA2, also known as FANCD1, has a more specific role in DNA repair and is directly involved in the mechanism of HR, regulating the activity of RAD51, a gene implicated in the HR pathway as well as interacting with PALB2, a gene implicated in the HR repair and checkpoint functions. Interestingly, the nuclear function of BRCA proteins is tightly regulated by the FA-BRCA, MMR, BER and NER pathway. However, the exact mechanisms of the BRCAassociated interaction and accumulation of other DNA repair proteins are not comprehensively known. Therefore, germline mutations in other susceptibility genes, such as FA genes, MMR genes and DNA repair genes, might be the predisposing factors in HBOC cases. These predisposing genes encode for upstream and downstream regulators of BRCA gene products and also may be associated with the BRCA core complex, including mutations in FANCD1, FANCD2, FANCJ, FANCP, TP53, PTEN, STK11, CDH1, CHK2, ATM, ATR, MSH1, M SH2, MLH1 and PMS2 genes. Families affected by other syndromes, such as Lynch syndrome (mutations in MMR genes), Fanconi anemia, Cowden syndrome (mutations in PTEN), Li-Fraumeni syndrome (mutations in TP53), xeroderma pigmentosum and ataxia-telangiectasia, exhibit additional types of cancers outside the previously defined HBOC cancer spectrum.

In conclusion, genetic or epigenetic loss-of-function mutations of genes that are known to be involved in the repair of DNA damage might lead to increased risk of developing a broad spectrum of breast and ovarian cancers.

\section{Acknowledgements}

Th present review was supported by grant-in-aid for Scientific Research from the Ministry of Education, Science, and Culture of Japan to the Department of Obstetrics and Gynecology, Nara Medical University (to H.K.).

\section{References}

1. Lynch HT, Lynch J, Conway T, Watson P, Feunteun J, Lenoir G, Narod S and Fitzgibbons R Jr: Hereditary breast cancer and family cancer syndromes. World J Surg 18: 21-31, 1994.

2. Ford D, Easton DF, Bishop DT, Narod SA and Goldgar DE: Risks of cancer in BRCA1-mutation carriers. Breast Cancer Linkage Consortium. Lancet 343: 692-695, 1994.

3. Sokolenko AP, Iyevleva AG, Mitiushkina NV, Suspitsin EN, Preobrazhenskaya EV, Kuligina ESh, Voskresenskiy DA, Lobeiko OS, Krylova NY, Gorodnova TV, Buslov KG, Bit-Sava EM, Dolmatov GD, Porhanova NV, Polyakov IS, Abysheva SN, Katanugina AS, Baholdin DV, Yanus GA, Togo AV, Moiseyenko VM, Maximov SY, Semiglazov VF and Imyanitov EN: Hereditary breast-ovarian cancer syndrome in Russia. Acta Nat 2: 31-35, 2010.

4. Smith KL and Isaacs C: BRCA mutation testing in determining breast cancer therapy. Cancer J 17: 492-499, 2011.

5. Ruan Y, Song AP, Wang H, Xie YT, Han JY, Sajdik C, Tian XX and Fang WG: Genetic polymorphisms in AURKA and BRCAI are associated with breast cancer susceptibility in a Chinese Han population. J Pathol 225: 535-543, 2011.

6. Zhang B, Beeghly-Fadiel A, Long J and Zheng W: Genetic variants associated with breast-cancer risk: comprehensive research synopsis, meta-analysis, and epidemiological evidence. Lancet Oncol 12: 477-488, 2011.

7. Narod SA and Salmena L: BRCA1 and BRCA2 mutations and breast cancer. Discov Med 12: 445-453, 2011.

8. Vasickova P, Machackova E, Lukesova M, Damborsky J, Horky O, Pavlu H, Kuklova J, Kosinova V, Navratilova M and Foretova L: High occurrence of $B R C A 1$ intragenic rearrangements in hereditary breast and ovarian cancer syndrome in the Czech Republic. BMC Med Genet 8: 32, 2007.

9. Walsh T and King MC: Ten genes for inherited breast cancer. Cancer Cell 11: 103-105, 2007.

10. Friedenson B: The BRCA1/2 pathway prevents hematologic cancers in addition to breast and ovarian cancers. BMC Cancer 7: 152, 2007. 
11. Cortesi L, Masini C, Cirilli C, Medici V, Marchi I, Cavazzini G, Pasini G, Turchetti D and Federico M: Favourable ten-year overall survival in a Caucasian population with high probability of hereditary breast cancer. BMC Cancer 10: 90, 2010.

12. Bolton KL, Chenevix-Trench G, Goh C, Sadetzki S, Ramus SJ, Karlan BY, Lambrechts D, Despierre E, Barrowdale D, McGuffog L, Healey S, Easton DF, Sinilnikova O, Benítez J, García MJ, Neuhausen S, Gail MH, Hartge P, Peock S, Frost D, Evans DG, Eeles R, Godwin AK, Daly MB, Kwong A, Ma ES, Lázaro C, Blanco I, Montagna M, D'Ándrea E, Nicoletto MO, Johnatty SE, Kjær SK, Jensen A, Høgdall E, Goode EL, Fridley BL, Loud JT, Greene MH, Mai PL, Chetrit A, Lubin F, Hirsh-Yechezkel G, Glendon G, Andrulis IL, Toland AE, Senter L, Gore ME, Gourley C, Michie CO, Song H, Tyrer J, Whittemore AS, McGuire V, Sieh W, Kristoffersson U, Olsson H, Borg A, Levine DA, Steele L, Beattie MS, Chan S, Nussbaum RL, Moysich KB, Gross J, Cass I, Walsh C, Li AJ, Leuchter R, Gordon O, Garcia-Closas M, Gayther SA, Chanock SJ, Antoniou AC and Pharoah PD; EMBRACE; kConFab Investigators; Cancer Genome Atlas Research Network: Association between $B R C A 1$ and $B R C A 2$ mutations and survival in women with invasive epithelial ovarian cancer. JAMA 307: 382-390, 2012

13. Dillenburg CV, Bandeira IC, Tubino TV, Rossato LG, Dias ES, Bittelbrunn AC and Leistner-Segal S: Prevalence of 185delAG and 5382insC mutations in BRCA1, and 6174delT in BRCA2 in women of Ashkenazi Jewish origin in southern Brazil. Genet Mol Biol 35: 599-602, 2012.

14. Ewald IP, Ribeiro PL, Palmero EI, Cossio SL, Giugliani R and Ashton-Prolla P: Genomic rearrangements in BRCAI and BRCA2: a literature review. Genet Mol Biol 32: 437-446, 2009.

15. Dent R, Trudeau M, Pritchard KI, Hanna WM, Kahn HK, Sawka CA, Lickley LA, Rawlinson E, Sun P and Narod SA: Triple-negative breast cancer: clinical features and patterns of recurrence. Clin Cancer Res 13: 4429-4434, 2007.

16. Gonzalez-Angulo AM, Timms KM, Liu S, Chen H, Litton JK Potter J, Lanchbury JS, Stemke-Hale K, Hennessy BT, Arun BK, Hortobagyi GN, Do KA, Mills GB and Meric-Bernstam F: Incidence and outcome of $B R C A$ mutations in unselected patients with triple receptor-negative breast cancer. Clin Cancer Res 17: 1082-1089, 2011

17. Young SR, Pilarski RT, Donenberg T, Shapiro C, Hammond LS, Miller J, Brooks KA, Cohen S, Tenenholz B, Desai D, Zandvakili I, Royer R, Li S and Narod SA: The prevalence of BRCA1 mutations among young women with triple-negative breast cancer. BMC Cancer 9: 86, 2009.

18. Holstege H, Joosse SA, van Oostrom CT, Nederlof PM, de Vries A and Jonkers J: High incidence of protein-truncating TP53 mutations in BRCA1-related breast cancer. Cancer Res 69 : 3625-3633, 2009.

19. Yates MS, Meyer LA, Deavers MT, Daniels MS, Keeler ER, Mok SC, Gershenson DM and Lu KH: Microscopic and earlystage ovarian cancers in BRCA1/2 mutation carriers: building a model for early BRCA-associated tumorigenesis. Cancer Prev Res 4: 463-470, 2011.

20. Tinker AV and Gelmon K: The role of PARP inhibitors in the treatment of ovarian carcinomas. Curr Pharm Des 18: 3770-3774, 2012.

21. Kaye SB, Lubinski J, Matulonis U, Ang JE, Gourley C, Karlan BY, Amnon A, Bell-McGuinn KM, Chen LM, Friedlander M, Safra T, Vergote I, Wickens M, Lowe ES, Carmichael $J$ and Kaufman B: Phase II, open-label, randomized, multicenter study comparing the efficacy and safety of olaparib, a poly (ADP-ribose) polymerase inhibitor, and pegylated liposomal doxorubicin in patients with BRCA 1 or BRCA2 mutations and recurrent ovarian cancer. J Clin Oncol 30: 372-379, 2012.

22. Ledermann J, Harter P, Gourley C, Friedlander M, Vergote I, Rustin G, Scott C, Meier W, Shapira-Frommer R, Safra T, Matei D, Macpherson E, Watkins C, Carmichael J and Matulonis U: Olaparib maintenance therapy in platinum-sensitive relapsed ovarian cancer. N Engl J Med 366: 1382-1392, 2012.

23. Vaezi A, Feldman $\mathrm{CH}$ and Niedernhofer LJ: ERCCl and $\mathrm{XRCCl}$ as biomarkers for lung and head and neck cancer. Pharmgenomics Pers Med 4: 47-63, 2011.

24. Chen Y, Toland AE, McLennan J, Fridlyand J, Crawford B, Costello JF and Ziegler JL: Lack of germ-line promoter methylation in BRCAl-negative families with familial breast cancer. Genet Test 10: 281-284, 2006.
25. Potapova A, Hoffman AM, Godwin AK, Al-Saleem T and Cairns P: Promoter hypermethylation of the PALB2 susceptibility gene in inherited and sporadic breast and ovarian cancer. Cancer Res 68: 998-1002, 2008.

26. Lynch HT, Casey MJ, Snyder CL, Bewtra C, Lynch JF, Butts M and Godwin AK: Hereditary ovarian carcinoma: heterogeneity, molecular genetics, pathology, and management. Mol Oncol 3: 97-137, 2009.

27. Vogel VG, Costantino JP, Wickerham DL, Cronin WM, Cecchini RS, Atkins JN, Bevers TB, Fehrenbacher L, Pajon ER Jr, Wade JL III, Robidoux A, Margolese RG, James J, Lippman SM, Runowicz CD, Ganz PA, Reis SE, McCaskillStevens W, Ford LG, Jordan VC and Wolmark N; National Surgical Adjuvant Breast and Bowel Project (NSABP): Effects of tamoxifen vs raloxifene on the risk of developing invasive breast cancer and other disease outcomes: the NSABP Study of Tamoxifen and Raloxifene (STAR) P-2 trial. JAMA 295: 2727-2741, 2006

28. McLaughlin JR, Risch HA, Lubinski J, Moller P, Ghadirian P, Lynch H, Karlan B, Fishman D, Rosen B, Neuhausen SL, Offit K, Kauff N, Domchek S, Tung N, Friedman E, Foulkes W, Sun P and Narod SA: Hereditary Ovarian Cancer Clinical Study Group: reproductive risk factors for ovarian cancer in carriers of BRCA1 or BRCA2 mutations: a case-control study. Lancet Oncol 8: 26-34, 2007.

29. Milne RL, Knight JA, John EM, Dite GS, Balbuena R, Ziogas A, Andrulis IL, West DW, Li FP, Southey MC, Giles GG, McCredie MR, Hopper JL and Whittemore AS: Oral contraceptive use and risk of early-onset breast cancer in carriers and noncarriers of $B R C A 1$ and $B R C A 2$ mutations. Cancer Epidemiol Biomarkers Prev 14: 350-356, 2005.

30. Domanska K, Malander S, Staaf J, Karlsson A, Borg A, Jönsson G and Nilbert M: Genetic profiles distinguish different types of hereditary ovarian cancer. Oncol Rep 24: 885-895, 2010.

31. Lotsari JE, Gylling A, Abdel-Rahman WM, Nieminen TT, Aittomäki K, Friman M, Pitkänen R, Aarnio M, Järvinen HJ, Mecklin JP, Kuopio T and Peltomäki P: Breast carcinoma and Lynch syndrome: molecular analysis of tumors arising in mutation carriers, non-carriers, and sporadic cases. Breast Cancer Res 14: R90, 2012.

32. Meyer LA, Broaddus RR and Lu KH: Endometrial cancer and Lynch syndrome: clinical and pathologic considerations. Cancer Control 16: 14-22, 2009

33. Masuda K, Banno K, Yanokura M, Kobayashi Y, Kisu I, Ueki A, Ono A, Nomura H, Hirasawa A, Susumu N and Aoki D: Carcinoma of the lower uterine segment (LUS): clinicopathological characteristics and association with lynch syndrome. Curr Genomics 12: 25-29, 2011.

34. Crijnen TE, Janssen-Heijnen ML, Gelderblom H, Morreau J, Nooij MA, Kenter GG and Vasen HF: Survival of patients with ovarian cancer due to a mismatch repair defect. Fam Cancer 4: 301-305, 2005.

35. Kim MK, Song SY, Do IG, Kim SH, Choi CH, Kim TJ, Lee JW, Bae DS and Kim BG: Synchronous gynecologic malignancy and preliminary results of Lynch syndrome. J Gynecol Oncol 22: 233-238, 2011.

36. Williams SA, Wilson JB, Clark AP, Mitson-Salazar A, Tomashevski A, Ananth S, Glazer PM, Semmes OJ, Bale AE, Jones NJ and Kupfer GM: Functional and physical interaction between the mismatch repair and FA-BRCA pathways. Hum Mol Genet 20: 4395-4410, 2011

37. Vogel VG, Costantino JP, Wickerham DL, Cronin WM, Cecchini RS, Atkins JN, Bevers TB, Fehrenbacher L, Pajon ER, Wade JL III, Robidoux A, Margolese RG, James J, Runowicz CD, Ganz PA, Reis SE, McCaskill-Stevens W, Ford LG, Jordan VC and Wolmark N: National Surgical Adjuvant Breast and Bowel Project: Update of the National Surgical Adjuvant Breast and Bowel Project Study of tamoxifen and raloxifene (STAR) P-2 trial: preventing breast cancer. Cancer Prev Res 3: 696-706, 2010.

38. Burga LN, Hu H, Juvekar A, Tung NM, Troyan SL, Hofstatter EW and Wulf GM: Loss of $B R C A 1$ leads to an increase in epidermal growth factor receptor expression in mammary epithelial cells, and epidermal growth factor receptor inhibition prevents estrogen receptor-negative cancers in BRCA1-mutant mice. Breast Cancer Res 13: R30, 2011.

39. Uray IP and Brown PH: Chemoprevention of hormone receptornegative breast cancer: new approaches needed. Recent Results Cancer Res 188: 147-162, 2011. 
40. Saito M, Matsuzaki M, Sakuma T, Katagata N, Watanabe F, Yamaguchi Y, Schetter AJ, Takenoshita S and Nomizu T: Clinicopathological study of non-palpable familial breast cancer detected by screening mammography and diagnosed as DCIS Breast Cancer: Aug 9, 2012 (Epub ahead of print).

41. Yabuuchi H, Matsuo Y, Sunami S, Kamitani T, Kawanami S, Setoguchi T, Sakai S, Hatakenaka M, Kubo M, Tokunaga E, Yamamoto $\mathrm{H}$ and Honda $\mathrm{H}$ : Detection of non-palpable breast cancer in asymptomatic women by using unenhanced diffusionweighted and T2-weighted MR imaging: comparison with mammography and dynamic contrast-enhanced MR imaging. Eur Radiol 21: 11-17, 2011.

42. Passaperuma K, Warner E, Causer PA, Hill KA, Messner S, Wong JW, Jong RA, Wright FC, Yaffe MJ, Ramsay EA, Balasingham S, Verity L, Eisen A, Curpen B, Shumak R, Plewes DB and Narod SA: Long-term results of screening with magnetic resonance imaging in women with BRCA mutations. Br J Cancer 107: 24-30, 2012.

43. Warner E, Hill K, Causer P, Plewes D, Jong R, Yaffe M, Foulkes WD, Ghadirian P, Lynch H, Couch F, Wong J, Wright F, Sun P and Narod SA: Prospective study of breast cancer incidence in women with a $B R C A 1$ or $B R C A 2$ mutation under surveillance with and without magnetic resonance imaging. J Clin Oncol 29: 1664-1669, 2011

44. Westin SN, Sun CC, Lu KH, Schmeler KM, Soliman PT, Lacour RA, Johnson KG, Daniels MS, Arun BK, Peterson SK and Bodurka DC: Satisfaction with ovarian carcinoma riskreduction strategies among women at high risk for breast and ovarian carcinoma. Cancer 117: 2659-2667, 2011.

45. Dohrn L, Salles D, Siehler SY, Kaufmann J and Wiesmüller L: BRCA1-mediated repression of mutagenic end-joining of DNA double-strand breaks requires complex formation with $\mathrm{BACH} 1$. Biochem J 441: 919-926, 2012.

46. Corso G, Marrelli D, Pascale V, Vindigni C and Roviello F: Frequency of $\mathrm{CDH} 1$ germline mutations in gastric carcinoma coming from high- and low-risk areas: metanalysis and systematic review of the literature. BMC Cancer 12: 8, 2012.

47. Chun N and Ford JM: Genetic testing by cancer site: stomach Cancer J 18: 355-363, 2012.

48. Lytras A and Tolis G: Reproductive disturbances in multiple neuroendocrine tumor syndromes. Endocr Relat Cancer 16: $1125-1138,2009$.

49. Melbārde-Gorkuša I, Irmejs A, Bērzina D, Strumfa I, Abolinš A, Gardovskis A, Subatniece S, Trofimovičs G, Gardovskis $\mathfrak{J}^{3}$ and Miklaševičs E: Challenges in the management of a patient with Cowden syndrome: case report and literature review. Hered Cancer Clin Pract 10: 5, 2012.

50. Buller RE, Lallas TA, Shahin MS, Sood AK, Hatterman-Zogg M, Anderson B, Sorosky JI and Kirby PA: The p53 mutational spectrum associated with $B R C A 1$ mutant ovarian cancer. Clin Cancer Res 7: 831-838, 2001.

51. Meng AG and Jiang LL: Induction of $\mathrm{G} 2 / \mathrm{M}$ arrest by pseudolaric acid $\mathrm{B}$ is mediated by activation of the ATM signaling pathway. Acta Pharmacol Sin 30: 442-450, 2009.

52. Lindeman GJ, Hiew M, Visvader JE, Leary J, Field M, Gaff CL, Gardner RJ, Trainor K, Cheetham G, Suthers G and Kirk J: Frequency of the ATM IVS10-6T $>$ G variant in Australian multiple-case breast cancer families. Breast Cancer Res 6 : R401-R407, 2004.

53. Wang X, Kennedy RD, Ray K, Stuckert P, Ellenberger T and D'Andrea AD: Chk1-mediated phosphorylation of FANCE is required for the Fanconi anemia/BRCA pathway. Mol Cell Biol 27: 3098-3108, 2007.

54. Kuusisto KM, Bebel A, Vihinen M, Schleutker J and Sallinen SL: Screening for BRCA1, BRCA2, CHEK2, PALB2, BRIP1, RAD50, and $C D H 1$ mutations in high-risk Finnish $B R C A 1 / 2$-founder mutation-negative breast and/or ovarian cancer individuals. Breast Cancer Res 13: R20, 2011.

55. de Garibay GR, Díaz A, Gaviña B, Romero A, Garre P, Vega A, Blanco A, Tosar A, Díez O, Pérez-Segura P, Díaz-Rubio E, Caldés T and de la Hoya M: Low prevalence of SLX4 loss-offunction mutations in non-BRCA1/2 breast and/or ovarian cancer families. Eur J Hum Genet: Dec 5, 2012 (Epub ahead of print).
56. Seal S, Thompson D, Renwick A, Elliott A, Kelly P, Barfoot R, Chagtai T, Jayatilake H, Ahmed M, Spanova K, North B, McGuffog L, Evans DG and Eccles D; Breast Cancer Susceptibility Collaboration (UK), Easton DF, Stratton MR and Rahman N: Truncating mutations in the Fanconi anemia J gene $B R I P 1$ are low-penetrance breast cancer susceptibility alleles. Nat Genet 38: 1239-1241, 2006.

57. Sy SM, Huen MS and Chen J: PALB2 is an integral component of the BRCA complex required for homologous recombination repair. Proc Natl Acad Sci USA 106: 7155-7160, 2009.

58. Willers H, Kachnic LA, Luo CM, Li L, Purschke M, Borgmann K, Held KD and Powell SN: Biomarkers and mechanisms of FANCD2 function. J Biomed Biotechnol 2008: 821529, 2008

59. Johnson N, Li YC, Walton ZE, Cheng KA, Li D, Rodig SJ, Moreau LA, Unitt C, Bronson RT, Thomas HD, Newell DR, D'Andrea AD, Curtin NJ, Wong KK and Shapiro GI: Compromised CDK1 activity sensitizes BRCA-proficient cancers to PARP inhibition. Nat Med 17: 875-882, 2011.

60. Clague J, Wilhoite G, Adamson A, Bailis A, Weitzel JN and Neuhausen SL: RAD51C germline mutations in breast and ovarian cancer cases from high-risk families. PLoS One 6: e25632, 2011

61. Hsu HM, Wang HC, Chen ST, Hsu GC, Shen CY and Yu JC: Breast cancer risk is associated with the genes encoding the DNA double-strand break repair Mre11/Rad50/Nbs1 complex. Cancer Epidemiol Biomarkers Prev 16: 2024-2032, 2007.

62. Meindl A, Hellebrand H, Wiek C, Erven V, Wappenschmidt B, Niederacher D, Freund M, Lichtner P, Hartmann L, Schaal H, Ramser J, Honisch E, Kubisch C, Wichmann HE, Kast K, Deissler H, Engel C, Muller-Myhsok B, Neveling K, Kiechle M, Mathew CG, Schindler D, Schmutzler RK and Hanenberg H: Germline mutations in breast and ovarian cancer pedigrees establish RAD51C as a human cancer susceptibility gene. Nat Genet 42: 410-414, 2010.

63. Pelttari LM, Heikkinen T, Thompson D, Kallioniemi A, Schleutker J, Holli K, Blomqvist C, Aittomäki K, Bützow R and Nevanlinna $\mathrm{H}$ : RAD $51 C$ is a susceptibility gene for ovarian cancer. Hum Mol Genet 20: 3278-3288, 2011.

64. Esteban Cardeñosa E, de Juan Jiménez I, Palanca Suela S, Chirivella González I, Segura Huerta A, Santaballa Beltran A, Casals El Busto M, Barragán González E, Fuster Lluch O, Bermúdez Edo J and Bolufer Gilabert P: Low penetrance alleles as risk modifiers in familial and sporadic breast cancer. Fam Cancer 11: 629-636, 2012

65. Jakubowska A, Gronwald J, Menkiszak J, Górski B, Huzarski T, Byrski T, Edler L, Lubiński J, Scott RJ and Hamann U: The $V E G F$ 936_C $>$ T 3'UTR polymorphism reduces BRCA1associated breast cancer risk in Polish women. Cancer Lett 262: 71-76, 2008.

66. Runnebaum IB, Wang-Gohrke S, Vesprini D, Kreienberg R, Lynch H, Moslehi R, Ghadirian P, Weber B, Godwin AK, Risch H, Garber J, Lerman C, Olopade OI, Foulkes WD, Karlan B, Warner E, Rosen B, Rebbeck T, Tonin P, Dubé MP, Kieback DG and Narod SA: Progesterone receptor variant increases ovarian cancer risk in BRCA1 and BRCA2 mutation carriers who were never exposed to oral contraceptives. Pharmacogenetics 11: 635-638, 2001.

67. Ratner E, Lu L, Boeke M, Barnett R, Nallur S, Chin LJ, Pelletier C, Blitzblau R, Tassi R, Paranjape T, Hui P, Godwin AK, Yu H, Risch H, Rutherford T, Schwartz P, Santin A, Matloff E, Zelterman D, Slack FJ and Weidhaas JB: A KRAS-variant in ovarian cancer acts as a genetic marker of cancer risk. Cancer Res 70: 6509-6515, 2010.

68. Ripperger T, Gadzicki D, Meindl A and Schlegelberger B: Breast cancer susceptibility: current knowledge and implications for genetic counselling. Eur J Hum Genet 17: 722-731, 2009. 